\title{
Study of Gall bladder contractility in patients of asymptomatic Gall stone
}

\author{
Dugar $D^{1}$, Khadanga $S^{2}$, Satapathy $S^{3}$, Tim $H^{4}$, Ghata $S^{5}$ \\ ${ }^{1}$ Dr Dharmendra Dugar, M.S. Assistant professor, Department of General surgery, ${ }^{2}$ Dr Sagar Khadanga, M.D. Assistant \\ Professor, Department of General Medicine, ${ }^{4}$ Dr Tim Houghton T, PG Student, Department of General surgery, ${ }^{5}$ Dr \\ Swarupjit Ghata, PG Student, Department of General surgery all are affiliated to Hi-Tech Medical College and Hospital, \\ Bhubaneswar, Odisha, India, ${ }^{3}$ Dr Shakti Satapathy, Consultant Radiologist, Care Hospital, Bhubaneswar, Odisha, India.
}

Address of corresponding author: Dr Dharmendra Dugar, E mail:dddugar@gmail.com

\begin{abstract}
Introduction: The prevalence of gall bladder stone varies widely in different parts of world. Worldwide gall stone disease is increasing. Knowledge of the predictive factors of the development and persistence of symptoms in gall stone patients play a key role in clinical decision making. The aim of this study is to evaluate the presence of predictive factors for biliary pain development in gall stone, stressing the role of gall bladder motility. Aims and objective: To study gall bladder contractility in patients of asymptomatic gall stone by ultrasound and to correlate with normal individuals. Material and methods: A hospital based observational study was conducted from January 2012 to march 2013. A total of 25 patients with asymptomatic gall stones (group 1) and 25 controls (group 2) were included in the study. Results: Ultrasonography volume was found to be significantly more in group 1, both during fasting and after fatty meals, suggesting decreased gall bladder motility in asymptomatic patient. Inter group comparison of gall bladder thickness was statistically significant both during fasting and after fatty meal in group. Conclusion: Gall bladder volume was found to be significantly more in asymptomatic cases, both during fasting and after fatty meal. Mean gall bladder wall thickness and mean alkaline phosphatase level was significantly more in patients with gall stones.
\end{abstract}

Key words: Alkaline phosphatase (ALP), Gall stone disease (GSD), Ultrasonography (USG),

\section{Introduction}

The prevalence of gall bladder stone varies widely in different parts of world. Worldwide gall stone disease is increasing $[1,2]$. An epidemiological study restricted to rail road workers showed that north Indians have 7 times higher occurrence of gall stone as compared with south Indians [3]. Presence of gall stones detected incidentally in patient who do not have any abdominal symptoms related to gall stone is known as asymptomatic cholelithiasis. The diagnosis is made during routine ultrasound for other abdominal condition.

The consideration of gall bladder motility and further risk factors (small stones, younger age and female gender) may help to predict the clinical course of gall stone patients, define atypical complaints as biliary related and select patients for treatment. Knowledge of the predictive factors of the development and persistence of symptoms in gall stone patients play a key role in clinical decision making. The aim of this

\footnotetext{
Manuscript received: $4^{\text {th }}$ July 2014

Reviewed: $17^{\text {th }}$ Aug 2014

Author Corrected: $24^{\text {th }}$ Aug 2014

Accepted for Publication: $25^{\text {th }}$ Aug 2014
}

study is to evaluate the presence of predictive factors for biliary pain development in gall stone, stressing the role of gall bladder motility. Gall bladder motility evaluation is a useful diagnostic tool in clinical decision making for gall stone in symptomatic patients; a progressive reduction of gall bladder motility could suggest a "wait and watch" management policy instead of an immediate surgical approach [4]. In this study we compared the effect of presence of gall stone over contractility in case and control group of asymptomatic gall stone patients. Patients with asymptomatic gall stone has less than $20 \%$ chances of ever developing symptoms, and the risk associated with prophylactic operation overweigh the potential benefit of surgery in most patients $[4,5]$.

\section{Aims and Objectives}

To study gall bladder contractility in patients of asymptomatic gall stone by ultrasound and to correlate with normal individuals. We compared gallbladder volume and wall thickness in patient of asymptomatic cholelithiasis and of normal individuals (control). 


\section{Methodology}

A hospital based observational study was conducted from January 2012 to march 2013. A total of 25 patients with asymptomatic gall stones (group 1) and 25 controls (group 2) were included in the study. Consecutive type of convenience sampling was used during the study period to select patients with asymptomatic gall stones.
All patients came to Hitech medical college and hospital who had asymptomatic gall stone diagnosed on ultrasonography were included in study.

\section{Exclusion criteria}

1. Asymptomatic gall stones with abnormal gall bladder on ultrasonography

2. Symptomatic gall stone disease

3. Complications of gall stone disease

\section{Inclusion criteria}

An ultrasonographic evaluation of fasting gall bladder volume and post-prandial volume was done in all subjects using 3.5 or $5 \mathrm{MHz}$ transducer. The probe was placed on the right subcostal area while the patients were in supine position and angled to obtain images showing largest longitudinal diameter of gall bladder.

The greatest length (L), the greatest width $(\mathrm{W})$ and anteroposterior $(\mathrm{H})$ dimensions and presence of gall stone were recorded. Gall bladder images were obtained after a standard breakfast consisting of egg, milk and pastry (695 kcal, $19.2 \mathrm{gm}$ carbohydrate and $9 \mathrm{gm}$ fat). The gall bladder volume was calculated by ellipsoid ( $\pi \times \mathrm{L} \times \mathrm{W} \times \mathrm{H})$.

\section{Results}

In our study out of 25 asymptomatic patients 12 were female. The age of the subject ranged from $10-80$ years. The mean age in group 1 and group 2 was $48.36 \pm 19.15$ and $44.28 \pm 16.31$ years respectively. Age difference was statistically non significant. None of the patient in group 1 had past history of any biliary tract involvement, jaundice, fever, pain or flatulent dyspepsia. In group-1, 13 patients presented with vague abdominal discomfort, 2 with umbilical hernia, 3 with benign hypertrophy of prostrate, 5 had renal calculi and 2 patients with appendicitis. None of the patients had symptoms pointing towards biliary tract involvement and were diagnosed with gall stones incidentally during ultrasonography.

Table 1: Intra group comparison of gall bladder wall thickness

\begin{tabular}{|l|l|l|l|}
\hline Group & Wall thickness in mm & Mean & p-value \\
\hline \multirow{3}{*}{ Group 1 } & Fasting & 2.41 & $<0.01$ \\
\cline { 2 - 3 } & After fatty meal & 2.57 & \\
\hline \multirow{2}{*}{ Group 2 } & Fasting & 2.21 & 0.95 \\
\cline { 2 - 3 } & After fatty meal & 2.23 & \\
\hline
\end{tabular}

There was significant increase in wall thickness in patients with asymptomatic gall stone disease as compared to control. Ultrasonography volume was found to be significantly more in group 1, both during fasting and after fatty meals (21.9 vs $12.9 \mathrm{ml}$ and 13.1 vs $4.6 \mathrm{ml}$ ), suggesting decreased gall bladder motility in asymptomatic patient [Table 2].

Fasting gall bladder volume is significantly more in group 1 with p-value $<0.01$ [Table 3]. Intergroup comparison of gall bladder volume was statistically significant ( $\mathrm{p}$-value $<0.01$ ), with higher volume after fatty meal, in group 1 [Table 4]. Gall bladder wall thickness was more in group 1, both in fasting [Table 3] and after fatty meal [Table 4], with p-value $<0.05$. Intragroup comparison of gall bladder wall thickness shows that the wall thickness is more in group 1 as compared to group 2 (2.41 vs $2.21 \mathrm{~mm}$ and $2.57 \mathrm{vs} 2.23 \mathrm{~mm}$ ) [Table 1].

Table 2: Intra group comparison of ultrasonography volume

\begin{tabular}{|l|l|l|l|}
\hline Group & Volume in $\mathbf{~ m l}$ & Mean & p-value \\
\hline \multirow{3}{*}{ Group 1 } & Fasting & 21.9 & $<0.01$ \\
\cline { 2 - 3 } & After fatty meal & 13.1 & \\
\hline \multirow{2}{*}{ Group 2 } & Fasting & 12.9 & $<0.01$ \\
\cline { 2 - 3 } & After fatty meal & 4.6 & \\
\hline
\end{tabular}

Ultrasonography volume was found to be significantly more in group 1, both during fasting and after fatty meals. 
Table 3: Inter-group comparison of gall bladder thickness and ultrasonography volume (fasting)

\begin{tabular}{|l|l|l|l|l|}
\hline Overnight fasting & Group & Mean & Standard deviation & P value \\
\hline \multirow{2}{*}{$\begin{array}{l}\text { Gall bladder } \\
\text { thickness }\end{array}$} & 1 & 2.41 & 1.62 & $<0.05$ \\
\cline { 2 - 5 } $\begin{array}{l}\text { Gall bladder } \\
\text { volume }\end{array}$ & 2 & 2.21 & 0.5 & \\
\cline { 2 - 5 } & 2 & 21.9 & 8.9 & $<0.01$ \\
\hline
\end{tabular}

Both volume and wall thickness is significantly higher in group 1 during fasting

Table 4: Inter-group comparison of gall bladder thickness and ultrasonography volume (after fatty meal)

\begin{tabular}{|l|l|l|l|l|}
\hline After fatty meal & Group & Mean & Standard deviation & P value \\
\hline \multirow{2}{*}{$\begin{array}{l}\text { Gall bladder } \\
\text { thickness }\end{array}$} & 1 & 2.57 & 1.58 & $<0.05$ \\
\cline { 2 - 4 } & 2 & 2.23 & 0.5 & \\
\hline \multirow{2}{*}{$\begin{array}{l}\text { Gall bladder } \\
\text { volume }\end{array}$} & 1 & 13.1 & 8.2 & $<0.01$ \\
\cline { 2 - 4 } & 2 & 4.6 & 2.0 & \\
\hline
\end{tabular}

Both volume and wall thickness is significantly higher in group 1 after fatty meal

\section{Discussion}

In our study 12 patients in group $1(48 \%)$ were females. Bhattacharya series [6] showed $71.4 \%$ were females while $28.6 \%$ were male. Similar sex preponderance in favour of females was noted in other studies. In the present study mean age in group 1 was $48.36 \pm 19.15$ years and group 2 was $44.28 \pm 16.31$ years. We found increased incidence of gall stones in the $6^{\text {th }}$ decade of life. Similar incidence is seen in the studies of Hamdani et al (65 years).

Ultrasonography volume was found to be significantly more in group 1 both during fasting and fatty meals (21.9 vs $12.9 \mathrm{ml}$ and $13.1 \mathrm{vs} 4.6 \mathrm{ml})$. Gall bladder motility in asymptomatic patients is decreased as compared to controls ( $\mathrm{P}$ value of $<0.01$ ). Brandt et al, in cross sectional study found that sluggish gall bladder motility was more frequent in asymptomatic patients [7].

Similar results were seen in studies by Nieves MA et al [8]. Brandt et al in a study on symptomatic and asymptomatic gall stone patients along with controls concluded that asymptomatic cholelithiasis is associated with impaired gall bladder function [9].

Intergroup comparison of gall bladder thickness was statistically significant both during fasting and after fatty meals ( 2.41 vs $2.21 \mathrm{~mm}$ and 2.57 vs $2.23 \mathrm{~mm}$ ). A study was conducted by Handler SJ et al to evaluate ultrasound of gall bladder wall thickening and its relation to gall bladder disease. The result showed that a thickened gall bladder wall is associated with gall stones [10]. A statistically significant increase in mean alkaline phosphatase was seen in patient with gall stone disease. Naseem A et al [11] found similar result.

\section{Conclusion}

Gall bladder volume was found to be significantly more in asymptomatic cases, both during fasting and after fatty meal, suggesting decreased gall bladder motility in asymptomatic gall stone patients compared to controls. Mean gall bladder wall thickness and mean alkaline phosphatase level was significantly more in patients with gall stones.

\section{Funding: Nil \\ Conflict of interest: Nil \\ Permission from IRB: Yes}

\section{References}

1. Caddy GR, Tham TC. Gallstone disease: Epidemiology, pathogenesis, and classification of biliary stones (common bile duct and intrahepatic). Best Pract Research clini Gastroenterol, 2006;20:1075-1083.

2. Shaffer EA. Gallstone disease: epidemiology of gall bladder stone disease Best Pract Res Clin Gastroenterol. 2006;20(6):981-96

3. Rakesh tendon, diseases of gall bladder and biliary tract. API text of medicine, Dr Siddharth N Shah, $7^{\text {th }}$ edition, 2003, 642-644

4. Ransohoff D, Gracie W. Treatment of gall stones. Ann intern med 1993 Oct 1;119(7 Pt 1):606-19

5. Ransohoff D, Gracie W, Wolfenson L, Neuhauser D. Prophylactic cholecystectomy or expectant management for silent gall stones: a decision analysis to assess survival. Ann Intern Med. 1983 Aug;99(2):199-204

Available online at: $\underline{\text { www.ijmrr.in }}$ 437 | P a g e 
6. Bhattacharya R, "Cholecystectomy in west port, New Zealand". Indian journal of surgery, august 1983, pp 102104

7. Brandt B, Lerche L, Stange E. Symptomatic or asymptomatic gall stone disease: is the gall bladder motility the clue? Hepatogastroenterology 2002 SepOct;49(47):1208-12.

8. Nieves MA, Gaona C, de Franco A. Gall bladder contraction in patient with asymptomatic cholelithiasis. G E N. 1990 Jan-Mar;44(1):35-40.
9. Brandt, J Groth , E F Stsngs, department of medicine, university of Luebeck, Germany. Fasting gall bladder volume and gall bladder emptying different in patients with symptomatic vrs asymptomatic stones. Biliary disorders. 1995; A407

10. Handler SJ. Ultrasound of gall bladder thickening and its relation to cholecystitis. AJR Am J Roentgenol. 1979 Apr;132(4):581-5

11. Naseem A Channa, Hafeez R Shaikh, Fateh D Khand, Muhammad I Bhanger and M H Laghari. Association of gall stone disease risk with serum level of alkaline phosphatase. JLUMHS, 2005;4(1):18-22

\section{How to cite this article?}

Dugar D, Khadanga S, Satapathy S, Tim HT, Ghata S. Study of Gall bladder contractility in patients of asymptomatic Gall stone. Int J Med Res Rev 2014;2(5):435- 438. doi:10.17511/ijmrr.2014.i05.06 